\title{
Evaluating the contribution of avalanching to the mass balance of Himalayan glaciers
}

\author{
Sourav LAHA, ${ }^{1}$ Reshama KUMARI, ${ }^{1}$ Sunil SINGH, ${ }^{2}$ Aditya MISHRA, ${ }^{2}$ Tushar SHARMA, ${ }^{2}$ \\ Argha BANERJEE, ${ }^{1}$ Harish Chandra NAINWAL, ${ }^{2}$ R. SHANKAR ${ }^{3}$ \\ ${ }^{1}$ Earth and Climate Science, Indian Institute of Science Education and Research, Pune, India \\ E-mail: argha@iisepune.ac.in \\ ${ }^{2}$ Department of Geology, HNB Garhwal University, Srinagar Garhwal, Uttarakhand 246174, India \\ ${ }^{3}$ The Institute of Mathematical Sciences, Chennai 600113, India
}

\begin{abstract}
Avalanching is a prominent source of accumulation on glaciers that have high and steep valley-walls surrounding their accumulation zones. These glaciers are typically characterised by an extensive supraglacial debris cover and a low accumulation area ratio. Despite an abundance of such glaciers in the rugged landscapes of the High Himalaya, attempts to quantify the net avalanche contribution to mass balance and its long-term variation are almost missing. We first discuss diagnostic criteria to identify strongly avalanche-fed glaciers. Second, we develop an approximate method to quantify the magnitude of the avalanche accumulation exploiting its expected control on the dynamics of these glaciers. The procedure is based on a simplified flowline model description of the glacier concerned and utilises the known glaciological mass-balance, velocity and surface-elevation profiles of the glacier. We apply the method to three Himalayan glaciers and show that the data on the recent dynamics of these glaciers are consistent with a dominant contribution of avalanches to the total accumulation. As a control experiment, we also simulate another Himalayan glacier where no significant avalanche contribution is expected, and reproduce the recent changes in that glacier without any additional avalanche contribution.
\end{abstract}

Keywords: Avalanches, debris-covered glaciers, glacier mass balance, glacier modelling

\section{INTRODUCTION}

It is rather well established that avalanches are a significant contributor to the net accumulation of ice on many glaciers in the high-relief Himalayan mountain range (Benn and Lehmkuhl, 2000; Benn and others, 2003; Scherler and others, 2011a; Nagai and others, 2014). However, the question of quantifying the avalanche accumulation and its longterm variability remains largely unexplored in the literature. If a broader understanding of the mass-balance processes in the Himalaya as well as in other glacierised regions in the world were to be achieved, a technique to address this issue must be developed. Such a development would be of help, on one hand to get a clearer picture of the recent climatic response of the Himalayan glaciers (Cogley, 2011; Scherler and others, 2011b; Kääb and others, 2012; Gardelle and others, 2013) and on the other hand to predict their future evolution reliably (Marzeion and others, 2012; Immerzeel and others, 2013).

A stochastic and highly localised accumulation of snow and ice on the inaccessible and often hazardous avalanche cones along the valley walls (Fig. 1) makes it difficult to directly measure the avalanche contribution using standard glaciological mass-balance techniques. However, neglecting this contribution would lead to a significant bias in the measurement of the mass balance. Therefore, standard manuals for mass-balance measurement advise against choosing glaciers where a strong avalanche activity is expected (Kaser and others, 2003). This is a serious limitation as far as Himalayan glaciers are concerned, where avalanche contributions often play a dominant role. For example, Scherler and others (2011a) have demonstrated that in several regions of the Himalaya the fraction of strongly avalanchefed glaciers is quite significant. They analyse three characteristic indicators of a strong avalanche activity: (1) high slopes in the ice-catchment area, (2) a high percentage of ice-free catchment above the snowline, and (3) low accumulation area ratio (AAR). Their data from a set of 287 glaciers in the Himalaya and Karakoram show that these characteristics are indeed correlated. In particular, almost all the glaciers with a AAR $<0.2$ have a very high percentage of ice-free catchment area above the snowline and, thus, are likely to be predominantly avalanche-fed ones. Such glaciers constitute $18 \%$ of the all the glaciers studied by them in the Western and South-Central Himalaya. This gives a ballpark estimate that in these regions of the Himalaya: it is likely that a significant percentage of the glaciers (about one in five) are strongly avalanche fed. Several models have been developed to estimate the snow redistribution due to gravitational processes, given the snowfall data and the topography (Gruber, 2007; Bernhardt and Schulz, 2010). However, a serious lack of reliable snowfall data in the glacierised high Himalaya (Viste and Sorteberg, 2015) limits the applicability of such tools in estimating avalanche contribution to the mass balance of a specific glacier. Moreover the ice-avalanche contribution to the mass balance of reconstituted glaciers (Benn and others, 2003) would not be captured by these methods. This necessitates an alternate indirect method for estimation of avalanche derived accumulation, possibly making use of available glaciological data. We hypothesise that the significant avalanche accumulation exerts dominant control on the observed pattern of shrinkage in these Himalayan glaciers. 


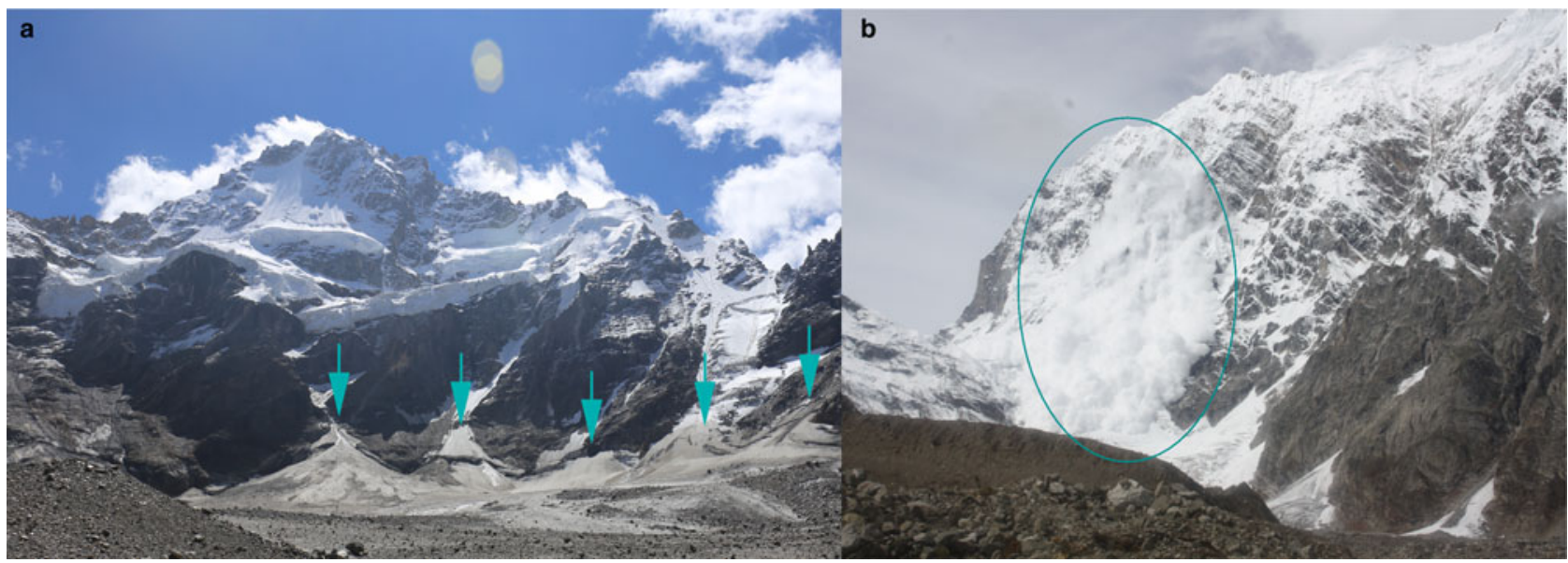

Fig. 1. (a) The headwall of Hamtah glacier showing large avalanche cones. (b) A massive avalanche rolling down from the Choukhamba massif $(7138 \mathrm{~m})$ at the headwall of Satopanth glacier.

If so, then this pattern of shrinkage can be utilised to quantify the avalanche contribution.

To test this hypothesis, in this paper we first discuss the diagnostic criteria that would allow identification of any strongly avalanche-fed glacier. Then we describe a simple and approximate method to obtain a first-order estimate of the possible avalanche contribution to mass balance using numerical flowline model simulations. The method requires as input the glaciological mass balance and the velocity/ thickness profile, long-term retreat and/or thinning-rate data and hypsometric data for the glacier chosen. The flowline model simulations are used to estimate the total accumulation that is consistent with all other available data related to glacier dynamics and glacier geometry. The difference between the modeled and glaciological mass balances, is assumed to be due to avalanche contributions. We cannot rule out various other possible sources of this residual accumulation contribution, e.g. any potential systematic bias in the accumulation measurement due to ill-chosen stake/pit locations or the effect of wind-driven inhomogeneous redistribution of snow and so on. However, we provide other circumstantial evidence drawn from the knowledge of the basin morphology etc. to argue that the estimated missing contribution should be dominantly coming from avalanche feeding. Here, we apply this method for Satopanth (30.73N, 79.32E) and Dunagiri (30.54N, 79.89E; also known as Dronagiri) Glaciers in the Central Himalaya and Hamtah Glacier $(32.22 \mathrm{~N}, 77.38 \mathrm{E})$ in the Western Himalaya (Table 1) where strong avalanche activity is suspected, and arrive at first order estimates for the values of the avalanche accumulation. We also perform a control simulation with Chhota Shigri Glacier $(32.28 \mathrm{~N}, 77.58 \mathrm{E})$, located $\sim 12 \mathrm{~km}$ to the west of Hamtah glacier in the western Himalaya, where avalanches are not expected to be an important source of nourishment and thereby check the consistency of our method.

\section{IDENTIFYING STRONGLY AVALANCHE-FED GLACIERS}

Glaciers with a strong avalanche contribution are usually associated with high and steep head-walls (Benn and others, 2003; Hughes, 2008; Scherler and others, 2011a; Nagai and others, 2014). Along with the snow and ice, avalanches from the head-wall and the lateral valley-walls bring down debris material to the accumulation zone, eventually leading to the formation of an extensive supraglacial debris mantle at the ablation zone (Benn and others, 2003; Kirkbride and Deline, 2013). The high relief, steep slopes and an abundance of extensively debris-covered glaciers in the Himalaya are thus indicative of a strong avalanche contribution for a significant fraction of them.

Benn and Lehmkuhl (2000) have argued that for any specific glacier, the steady-state AAR value goes down strongly with a relatively high contribution from avalanches to total accumulation as compared to that of the direct snowfall. The large-scale remote sensing data of Scherler and others (2011a) show that there is indeed a clear correlation of small AAR values with various proxies of strong avalanche activity in the Himalaya-Karakoram, namely, high slopes in the ice-catchment areas, and a high percentage of ice-free catchment above the snowline. Therefore, any glacier that has a very low $(<0.2)$ AAR, but does not show signs of fast retreat or high down-wasting, may be a strongly avalanchefed one.

Hughes (2008) has proposed that a high value of the ratio $(R)$ of the total avalanche-release area to the total area of a

Table 1. Observed glacier properties

\begin{tabular}{|c|c|c|c|c|c|c|c|c|}
\hline $\begin{array}{l}\text { Glacier } \\
\text { name }\end{array}$ & $\begin{array}{l}\text { Area } \\
\mathrm{A} \\
\mathrm{km}^{2}\end{array}$ & $\begin{array}{c}\text { Accumulation- } \\
\text { area ratio } \\
\alpha\end{array}$ & $\begin{array}{l}\text { Debris- } \\
\text { covered } \\
\text { fraction }\end{array}$ & $\begin{array}{l}\text { Avalanche- } \\
\text { release zone }(\mathrm{C}) \\
\mathrm{km}^{2}\end{array}$ & $R\left(\frac{C}{A}\right)$ & $R^{\prime}\left(\frac{C}{\alpha A}\right)$ & $\begin{array}{l}\text { Retreat rate } \\
\text { (period) } \\
\mathrm{m} \mathrm{a}^{-1}\end{array}$ & $\begin{array}{l}\text { Glaciological mass } \\
\text { balance } \mathrm{m} \text { w.e. } \mathrm{a}^{-1}\end{array}$ \\
\hline Satopanth & 19.0 & 0.18 & 0.56 & 15.2 & 0.8 & 4.4 & $5.6 \pm 0.7(1957-2013)$ & $-2.0(2015)$ \\
\hline Dunagiri & 2.4 & 0.13 & 0.85 & 1.9 & 0.8 & 6.1 & $9.0 \pm 0.6(1963-2013)$ & $-1.0(1984-1990)$ \\
\hline Hamtah & 3.7 & 0.14 & 0.68 & 2.5 & 0.7 & 4.8 & $25.5(1963-2010)$ & $-1.45(2000-2009)$ \\
\hline Chhota Shigri & 15.7 & 0.46 & 0.04 & 4.3 & 0.3 & 0.6 & $25(1972-2006)$ & $-0.57(2002-2012)$ \\
\hline
\end{tabular}


glacier indicates a strong avalanche contribution on that glacier. He has defined the avalanche-release zone to be the region of the headwall that has slope larger than $30^{\circ}$ and is connected to the accumulation zone. However, extensive debris cover that is often associated with strong avalanche activity, suppresses ablation leading to a larger glacier area (Banerjee and Shankar, 2013). This effect reduces the sensitivity of Hughes' ratio $(R)$ to the presence of avalanche contribution in debris-covered glaciers (Table 1). As an alternative, we use the ratio of the estimated map area of the avalanche-release zone to the map area of the accumulation zone $\left(R^{\prime}\right)$ to identify a significant avalanche activity on any given glacier. This may work better for the debris-covered glaciers since the total accumulation due to the direct solid precipitation (avalanching) is proportional to the area of the accumulation zone (avalanche-release zone) irrespective of the presence of a debris cover. We have estimated $R^{\prime}$ to be $4.8,4.4$ and 6.1 on Hamtah, Satopanth and Dunagiri glaciers, respectively (Table 1 ). These values are, for example, an order of magnitude larger than the corresponding values of 0.6 and 0.9 obtained respectively on Chhota Shigri and Dokriani glaciers - two other Himalayan glaciers with available glaciological massbalance record from the Western and Central Himalaya. This is a clear pointer towards strong avalanche contributions on Hamtah, Satopanth and Dunagiri glaciers, whereas Dokriani and Chhota Shigri Glaciers may not be receiving any such major avalanche contribution.

Incidentally, out of the set of $\sim 15$ glaciers in the Himalaya where glaciological mass-balance data are available, Dunagiri $\left(-1.0 \mathrm{~m}\right.$ w.e. $\left.\mathrm{a}^{-1}\right)$ and Hamtah glacier $(-1.45 \mathrm{~m}$ w.e. $\left.\mathrm{a}^{-1}\right)$ are the ones with the most negative mass-balance values (Vincent and others, 2013). Similarly, as described later, our data from Satopanth glacier for 2015 yields a negative mass balance of $-2.0 \mathrm{~m}$ w.e. $\mathrm{a}^{-1}$. In Hamtah and Dunagiri Glaciers the details of the accumulation measurement eg, pit locations, total number of pits, etc. are not available. On Satopanth glacier accumulation is not measured directly and is obtained by extrapolation. In spite of possible uncertainty in the accumulation measurements, such large negative values of mass balance, along with above-mentioned morphological characteristics, indicate a strong avalanche activity on these glaciers that may have remained unaccounted for in the glaciological massbalance estimates.

\section{ESTIMATION OF THE PUTATIVE AVALANCHE CONTRIBUTION}

\section{Rationale and method}

Our basic postulate is that for any strongly avalanche-fed glacier the glaciological mass balance, which typically does not measure the avalanche contribution, would have a significant negative bias. The glaciological mass balance would then be inconsistent with the observed state and the recent history of the glacier. For example, if the glacier is in a steady state, then the observed steady-state length would be much larger than the length that is consistent with the mass balance. For a retreating glacier, both the long-term retreat rate and the thinning rate may be much smaller than the observed values. It may be noted that since avalanchefed glaciers are also typically debris covered, they may take a characteristically long time, to show any length retreat even as they lose mass through the thinning of a stagnant tongue after a sharp warming takes place (Banerjee and Shankar, 2013). For such stagnant glaciers, it is important to compare the thinning rates. To observe the discrepancies mentioned above, multi-decadal to century-scale data on thinning and/or retreat are required due to the long response time of such extensively debris-covered glaciers.

Given the above assumption, the avalanche contribution can be estimated by simulating recent evolution of the glacier concerned. Any instantaneous transient state of a glacier in general can be specified by the ice thickness profile for a given bedrock. To arrive at the right transient state, we start with a steady state the length of which is much larger than that of the present transient state and force it with a suitable negative mass balance till a state with reasonable length, velocity and surface profiles are obtained. To make sure that our results are not dependent on the choice of initial steady state, we use more than one initial steady state. Once an approximation of any initial state is constructed, the glacier evolution can subsequently be simulated with the observed mass balance. If this results in a model state that is shrinking much faster than the observed loss rates, it signals the presence of a missing accumulation contribution for the glacier.

In order to estimate the actual magnitude of such a missing term, an arbitrary constant accumulation term is added and is adjusted till the simulated rate of recent thinning and retreat match the observed values. While there may be a complex spatio-temporal pattern of avalanche accumulation on the real glacier, that need not be prescribed in detail for a reasonable fit to the observed glacier-averaged shrinkage rates as long as the net avalanche accumulation is captured correctly. This is due to the strongly diffusive nature of ice flow, which smooths out any observable effects of such variability on the glacier dynamics. This also implies that our method would only allow estimation of long-term mean values of the magnitude of the avalanche contribution, as the diffusive ice-dynamics filters out the details of the short wavelength and high frequency spatio-temporal variability of the contribution.

\section{The flowline model}

The method discussed above can be implemented using a simple 1-D flowline model of glacier dynamics. A flowline model describes the time evolution of the thickness profile, $h(x, t)$, of a glacier along the central flowline parametrised by the distance $x$ [e.g., Banerjee and Shankar (2013)] as,

$$
\frac{\partial h}{\partial t}=-\frac{1}{w} \frac{\partial}{\partial x}(w h u)+\dot{b},
$$

where $w(x)$ is the width of the glacier at the point $x, u(x, t)$ the vertically averaged velocity and $\dot{b}(x, t)$ the point annual mass-balance rate in ice-equivalent unit. Note that throughout this paper we use 'mass balance' to designate mass-balance rates with units $m$ w.e. $a^{-1}$. Also, the waterequivalent rates as used otherwise in this paper can easily be recovered from ice-equivalents (Cogley and others, 2011). The ice velocity is related to the ice thickness through a constitutive relation derived under the shallowice approximation,

$$
u=\left(\rho g h\left(-s+\frac{\partial h}{\partial x}\right)\right)^{3}\left(\frac{f_{\mathrm{s}}}{h}+f_{\mathrm{d}} h\right) .
$$


$\rho$ is the ice density and $g$ is the acceleration due to gravity and $s$ the bedrock slope. $f_{\mathrm{s}}$ and $f_{\mathrm{d}}$ are parameters controlling the sliding and deformation contributions to the total flow. Oerlemans (2001) has suggested a value of $5.7 \times 10^{-20}$ $\mathrm{Pa}^{-3} \mathrm{~m}^{2} \mathrm{~s}^{-1}$ and $1.9 \times 10^{-24} \mathrm{~Pa}^{-3} \mathrm{~s}^{-1}$ for $f_{\mathrm{s}}$ and $f_{\mathrm{d}}$, respectively. However, the $f_{\mathrm{s}}$ and $f_{\mathrm{d}}$ values are typically used as a tuning parameters of the model (Adhikari and Huybrechts, 2009). The values used in modelling various glaciers in the Himalaya are in the range $0.19-1.75 \times 10^{-20} \mathrm{~Pa}^{-3} \mathrm{~m}^{2} \mathrm{~s}^{-1}$ for $f_{\mathrm{s}}$ and $1.7-5.3 \times 10^{-25} \mathrm{~Pa}^{-3} \mathrm{~s}^{-1}$ for $f_{\mathrm{d}}$ (Adhikari and Huybrechts, 2009; Venkatesh and others, 2012; Banerjee and Shankar, 2013; Banerjee and Azam, 2016). Starting with an initial thickness distribution, if the mass-balance profile as a function of time are known, then Eqn (2) can be used to find out $h(x, t)$ at all subsequent time $t$ for any given bedrock geometry and width distribution. If the mass balance does not vary with time then the glacier reaches a corresponding unique steady-state profile after a characteristic time, independent of the input initial thickness profile.

\section{Implementation}

We start with the surface-elevation profile along the central flowline and the mass-balance profile of the glacier concerned. Depending on the surface-elevation profile, we pick a piece-wise linear bedrock with two to three segments. We assign a width for each grid point on the bedrock, so that the bedrock has the same area-elevation distribution as the present glacier. We then simulate the glacier with a range of values of avalanche contribution added around the top of the glacier, such that corresponding steady-state lengths are longer than present glacier length. Subsequently, we simulate the glacier as the avalanche term reduces at a constant rate and store the intermediate transient states. The experiment is repeated for several values of the above rate of reduction. Then we plot data for all the intermediate states along with the corresponding observed data, and search for the right set of states so that the initial glacier surface-elevation and/or velocity profiles, glacier length, approximately match the observed data that is available for that glacier. The chosen transient state initial state is then evolved with the avalanche term fixed at its initial value. At this stage, we also tune the constant flow parameters $f_{\mathrm{s}}$ and $f_{\mathrm{d}}$ within reasonable limits, to the surface-velocity and thickness profile, retreat rate and net balance of the simulated state so that a reasonable match with the corresponding observed data is achieved (see Figs 4-6). If a good match is not found at this stage, we change the bedrock profile and repeat the whole procedure. While the actual glacier geometry might be more complex and there could be complications of tributaries etc., in the end our initial configuration has similar length, area-elevation distribution and a similar central-line velocity profile compared to the real glacier. This should ensure a similar dynamical behaviour in both the simulated and the real glaciers. We refer to the above numerical procedure as experiment (1). Subsequently, we perform another experiment, experiment (2). Here, the initial transient profile, as obtained above, is forced only with the glaciological mass-balance profile, with the constant avalanche term turned off, to see if it is consistent with observed recent dynamics of the glacier. Depending on the available data, we run these experiments for up to 50 years or more.

Given the approximate nature of our method and the uncertainty implicit in the input data, we tune the parameters by trial and error to produce a reasonable match with the observed data to the eye. In view of the large uncertainties of the data used, we decided not to apply a systematic fitting procedure here and limited ourselves to explore the sensitivity of our results to various tunable model parameters and the choice of the initial state. These details are described in the Results and Discussions section.

\section{Satopanth glacier}

For Satopanth Glacier (Fig. 2a), a front-averaged retreat rate of $5.6 \pm 0.7 \mathrm{~m} \mathrm{a}^{-1}$ during $1957-2013$, and a thinning rate of $0.18 \pm 0.22 \mathrm{~m} \mathrm{a}^{-1}$ on the lower ablation zone during 1962-2013 has been reported (Nainwal and others, 2016). The mean velocity profile for the period 2000-07, as obtained from remote-sensing data (Scherler and others, 2011a), and the surface-profile data for the year 2000 from Shuttle Radar Topographic Mission (SRTM1) DEM (Farr and others, 2007) are used.

The mass-balance measurement for this glacier has been initiated by our group during 2014 and the results would be reported in detail in a separate publication in the future. Here, we use our preliminary data for the massbalance year October 2014 to October 2015 that is derived from 40 stakes distributed over an elevation range of 3950-4625 $\mathrm{m}$ on the accessible stretches of the glacier (Fig. 2a). From the stake data, two best-fit elevationdependent linear mass-balance profiles are extracted - one
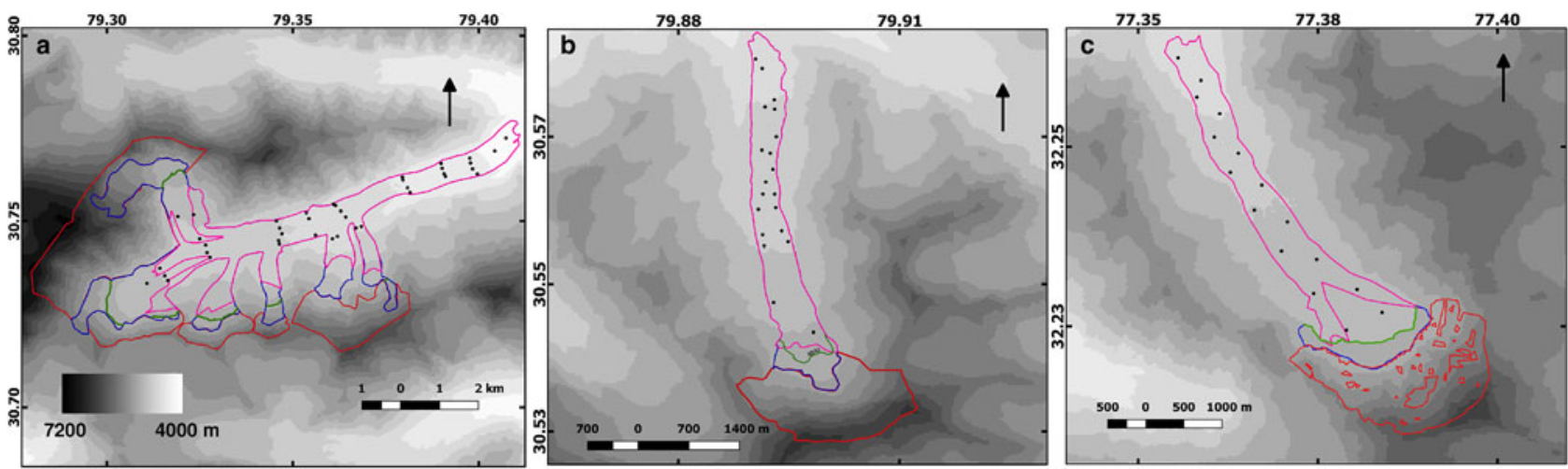

Fig. 2. Maps showing glacier boundary (blue), the extent debris cover (pink), potential avalanche release zone (red) for (a) Satopanth glacier, (b) Dunagiri glacier and (c) Hamtah glacier. The background is the $200 \mathrm{~m}$ grey-scale contour map of SRTM1 DEM. The corresponding ELAs are shown as green lines. Approximate stake locations are shown as black dots. 
each for the debris-covered and the debris-free ice, respectively. For the inaccessible debris-free part at the higher reaches of the glacier where no stake data is available, the mass-balance values are extrapolated using the above linear profile with an upper cut-off of $1.5 \mathrm{~m}$ w.e. $\mathrm{a}^{-1}$ applied to the accumulation values. To compute the mass balance in each elevation band, we use the sum of the two mass-balance values weighted by the corresponding debriscovered and debris-free ice fraction at that elevation band (Fig. 3). The equilibrium line altitude (ELA) of $4910 \mathrm{~m}$ obtained from the extrapolation of the linear mass-balance profile for the debris-free ice compares well with the independent estimate of $4840 \mathrm{~m}$ from the highest position of the end-of-summer transient snowline elevation as observed in cloud-free Landsat scenes from the year 2013 and 2016. To model the glacier during experiment (1), the added avalanche is spread uniformly over the region within the elevation band $5425-4600 \mathrm{~m}$.

\section{Dunagiri glacier}

For Dunagiri Glacier (Fig. 2b), a long-term retreat rate of $9 \pm$ $0.6 \mathrm{~m} \mathrm{a}^{-1}$ has been reported (Kumar and others, 2016) for the period 1962-2013. Field data on the surface velocities and mass-balance profile are available for the period 1984-90 (Srivastava and Swaroop, 1992). We use the data of 1986/ 87 as the corresponding mass balance is similar to the mean mass balance for the whole observation period - a value of $-1.0 \mathrm{~m}$ w.e. $\mathrm{a}^{-1}$. The mass-balance profile used (Fig. 3) is a piece-wise linear approximation of the data. The surface profile of the glacier along the central flowline is obtained using the $50 \mathrm{~m}$ contour map available for the year 1986/87 (Srivastava and Swaroop, 1992). In this glacier, the added avalanche is spread uniformly over the first kilometer of the glacier during experiment (1).

\section{Hamtah glacier}

Hamtah Glacier (Fig. 2c) has previously been studied by two of the authors ( $A B$ and $R S)$ to derive an estimate of the avalanche contribution of $1.3 \pm 0.1 \mathrm{~m}$ w.e. $\mathrm{a}^{-1}$ on that glacier (Banerjee and Shankar, 2014). The method was based on a highly simplified flowline model and depended crucially on a relatively uncertain estimate of the steady-state length of the glacier corresponding to the recent mass balance. We have recomputed the avalanche strength on this glacier

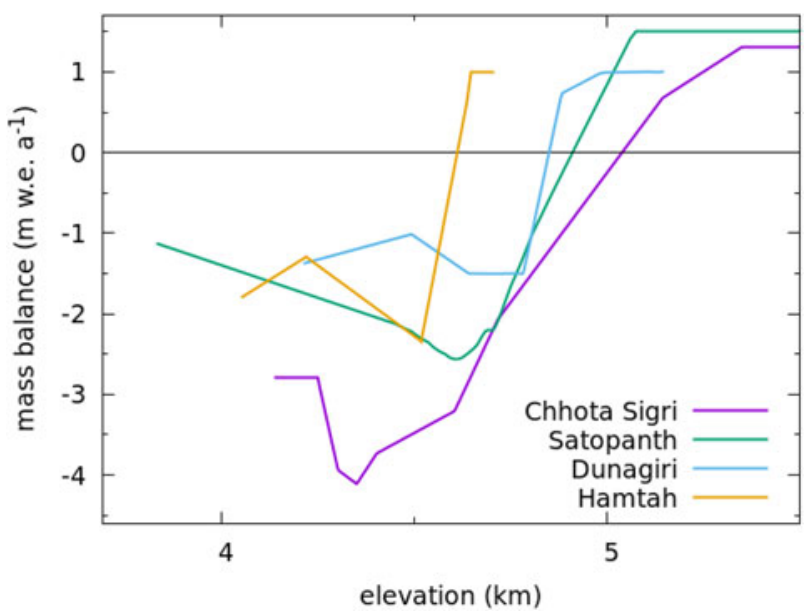

Fig. 3. The mass-balance profiles for the four modeled glaciers. using the method described here. We now use a more detailed area-elevation distribution, a piece-wise linear bedrock and the surface profile data from SRTM1 DEM (Farr and others, 2007). Also, in the present calculation only an initial transient state is used, without any assumption about a nearby steady state.

The velocity data for the glacier is again from remotesensing measurements (Scherler and others, 2011b) and the central flowline profile and the glacier hypsometry are extracted from SRTM1 (Farr and others, 2007). The longterm front-averaged retreat rate for the glacier is $25.5 \mathrm{~m} \mathrm{a}^{-1}$ during 1963-2010 (Pandey and others, 2011) and the recent glaciological net balance is $-1.45 \mathrm{~m} \mathrm{w.e.} \mathrm{a}^{-1}$ during 2000-09 as measured by Geological Survey of India (Shukla and others, 2015). However, during 1989-2010 the front averaged retreat rate has come down to $13 \mathrm{~m} \mathrm{a}^{-1}$ (Pandey and others, 2011). The mass-balance profile used in the simulation is a linear approximation of the available data for the mass-balance year 2008/09 (Banerjee and Shankar, 2014), that has similar mass balance as the mean value for the whole period. Avalanche contribution is again uniformly distributed over the grid points within the first kilometer from the top of the glacier.

\section{Chhota Shigri glacier}

In Chhota Shigri Glacier, where any significant avalanche contribution is not expected as argued before, a retreat rate of $25 \mathrm{~m} \mathrm{a}^{-1}$ for the period of 1972-2006 (Ramanathan, 2011), a geodetic mass balance of $-0.17 \pm 0.09 \mathrm{~m}$ w.e. $\mathrm{a}^{-1}$ during 1988-2010, and a glaciological mass balance of $-0.57 \pm 0.40 \mathrm{mw}$.e. $\mathrm{a}^{-1}$ during 2002-12 (Azam and others, 2014) have been reported. The observed mean ELA during the period of 2002-10 is $5075 \mathrm{~m}$ (Azam and others, 2012). The velocity data for the glacier is obtained from remote-sensing measurements (Scherler and others, 2011b) and the central flowline profile and the glacier hypsometry are from SRTM1 (Farr and others, 2007). To make the highest elevation of the selected central flowline consistent with the SRTM1 DEM-derived glacier hypsometry, we shift the elevation and velocity profile by a horizontal distance of $850 \mathrm{~m}$.

\section{RESULTS AND DISCUSSIONS}

Below, we discuss the results obtained from the above model runs for each of the glaciers modeled. Corresponding observed and modeled surface profile and velocity profiles are shown in Figs 4, 5. The results are also summarised in Table 2.

\section{Satopanth glacier}

The simulated recent state of Satopanth glacier has a mass balance of $-2.0 \mathrm{~m}$ w.e. $\mathrm{a}^{-1}$ if only the glaciological estimate is considered. However, in experiment (1) a net avalanche contribution of $1.8 \mathrm{~m}$ w.e. $\mathrm{a}^{-1}$ is needed to produce a mean retreat rate of $7.5 \mathrm{~m} \mathrm{a}^{-1}$ and a net thinning of the lower ablation zone by $0.18 \mathrm{~m}$ w.e. $\mathrm{a}^{-1}$ during 19602010, which are similar to the corresponding observed values. Without any additional avalanche term (experiment (2)), the glacier thins fast with rates of $2.0 \mathrm{~m}$ w.e. $\mathrm{a}^{-1}$ during 1960-2010. Moreover, the ice-flow velocity at the upper ablation zone vanishes quickly, leading to a complete detachment off the lower part (Fig. 5a). Any such detachment 

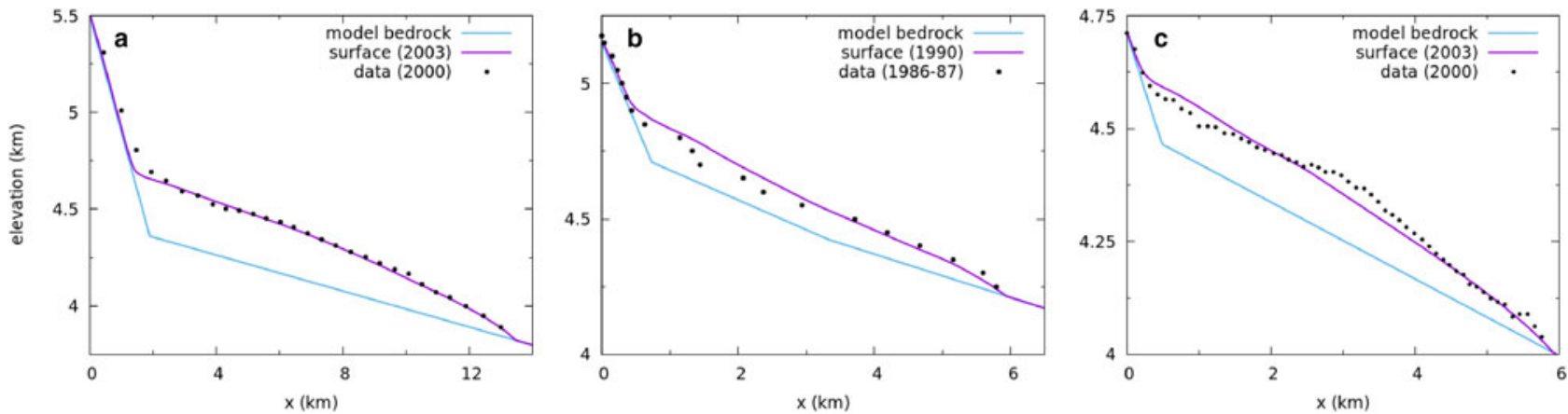

Fig. 4. The comparison of the observed and modeled surface elevation profiles for the recent states of (a) Satopanth, (b) Dunagiri and (c) Hamtah Glaciers. Note different horizontal scale in panel (a).

or strong slowdown has not been observed in the field. For example, our recent measurements of surface flow velocities during 2014/15 on the upper stakes indicate healthy velocities of more than $50 \mathrm{~m} \mathrm{a}^{-1}$. Therefore, the present retreating state of this glacier is not that far away from a steady state and is getting nourished by an avalanche contribution with an estimated magnitude of the order of $1.8 \mathrm{~m}$ w.e. $\mathrm{a}^{-1}$. This contribution added to the glaciological mass balance yields a residual of $-0.2 \mathrm{~m}$ w.e. $\mathrm{a}^{-1}$, which is a revised estimate for recent mass balance of this glacier. A possible geodetic mass-balance measurement can be used to verify this claim. Remarkably, the frontal retreat rate remains the same in both the experiments - this is not unexpected as due to a long response time and low ice flow velocities near the terminus, the retreat rate is chiefly controlled by the local icethickness profile in the lowermost part the glacier.

\section{Dunagiri glacier}

In Dunagiri glacier, where the recent glaciological mass balance is $-1.0 \mathrm{~m}$ w.e. $\mathrm{a}^{-1}$, a avalanche contribution of $0.7 \mathrm{~m}$ w.e. $\mathrm{a}^{-1}$ is necessary to obtain a realistic retreat rate of $12.5 \mathrm{~m} \mathrm{a}^{-1}$ over the past 50 years (Fig. 5b). Without the avalanche term, this glacier displays a thinning rate of $-1.0 \mathrm{~m}$ w.e. $\mathrm{a}^{-1}$ and flow velocity reduces rapidly all across the ablation zone. The future runs again suggest a
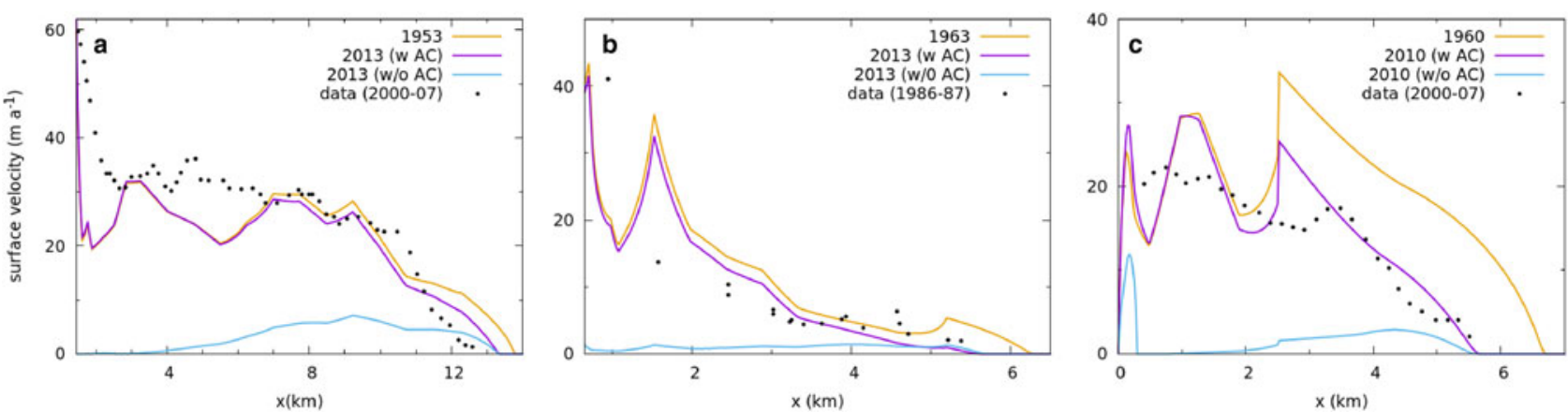

Fig. 5. The modeled velocity profile (solid line) for (a) Satopanth, (b) Dunagiri and (c) Hamtah glacier for the initial and recent states are shown for the runs with and without added avalanche contribution (AC). The dots denote available velocity data.
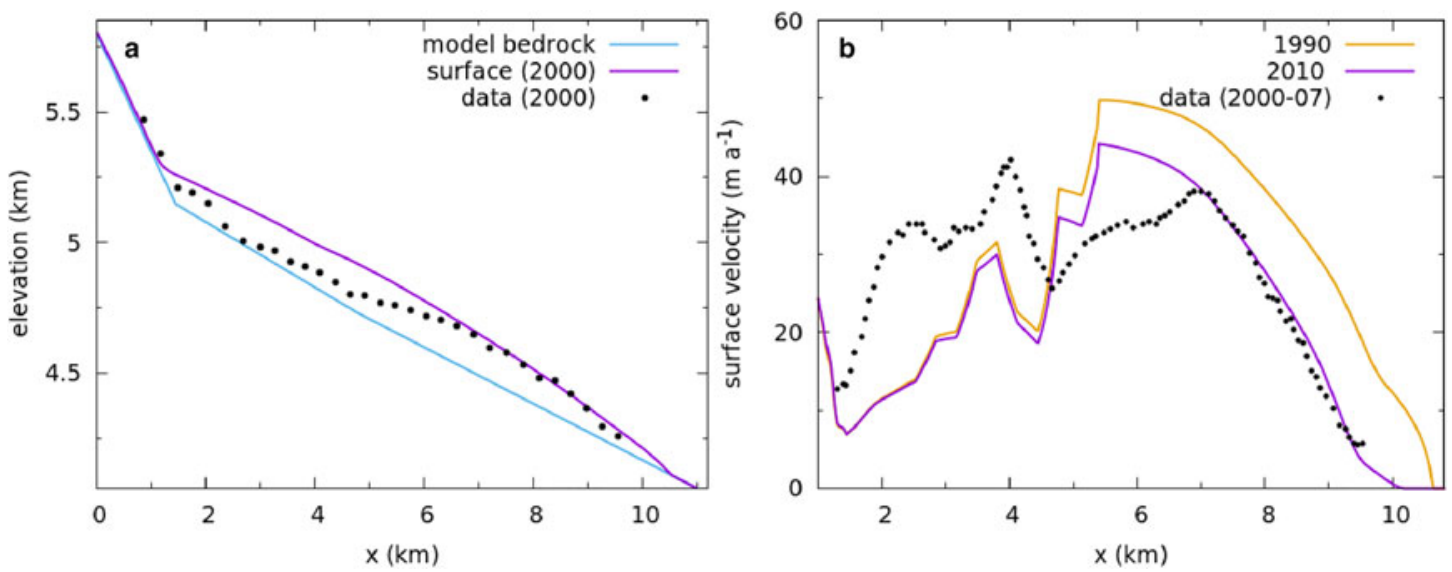

Fig. 6. (a) Comparison of the observed and modeled surface elevation profiles for the recent states Chhota Shigri Glacier. (b) The modeled velocity profile (solid line) for the initial and recent states are shown. The dots denote the observed velocities for the corresponding recent state. 
Table 2. Model parameter and results

\begin{tabular}{|c|c|c|c|c|c|c|}
\hline $\begin{array}{l}\text { Glacier } \\
\text { name }\end{array}$ & $\begin{array}{c}10^{-20} \times f_{\mathrm{s}} \\
{[\text { See Eqn }(2)]} \\
\mathrm{Pa}^{-3} \mathrm{~m}^{2} \mathrm{~s}^{-1}\end{array}$ & $\begin{array}{c}10^{-25} \times f_{\mathrm{d}} \\
{[\text { See Eqn }(2)]} \\
\mathrm{Pa}^{-3} \mathrm{~s}^{-1}\end{array}$ & $\begin{array}{c}\text { Modelled mass } \\
\text { balance }\left(\Delta m_{1}\right) \\
\text { m w.e. } \mathrm{a}^{-1}\end{array}$ & $\begin{array}{c}\text { Avalanche } \\
\text { contribution }\left(\Delta m_{2}\right) \\
\text { m w.e. } \mathrm{a}^{-1}\end{array}$ & $\begin{array}{c}\text { Residual } \\
\Delta m_{1}+\Delta m_{2} \\
\text { m w.e. } \mathrm{a}^{-1}\end{array}$ & $\begin{array}{l}\text { Retreat rate } \\
\text { (period) } \\
\mathrm{m} \mathrm{a}^{-1}\end{array}$ \\
\hline Satopanth & 4.9 & 1.4 & -2.0 & $1.8 \pm 0.5$ & $-0.2 \pm 0.5$ & 7.5 (1953-2013) \\
\hline Dunagiri & 1.0 & 1.1 & -1.0 & $0.7 \pm 0.2$ & $-0.3 \pm 0.2$ & $12.5(1960-2010)$ \\
\hline Hamtah & 3.4 & 1.3 & -1.5 & $1.0 \pm 0.3$ & $-0.5 \pm 0.3$ & $20.5(1960-2010)$ \\
\hline Chhota Shigri & 1.6 & 1.3 & -0.6 & 0 & -0.6 & $22.6(1990-2010)$ \\
\hline
\end{tabular}

complete detachment of the ablation zone from the headwall within 20 years (Fig. 5b). Though velocity data is not available for the current decade to crosscheck, a slowdown by a factor of 5 or more in the upper ablation zone over the past 20 years, and a complete detachment of the ablation zone over the next 20 years seem unlikely. Therefore, it is likely that the mass balance of the glacier over past 50 years is in fact $\sim-0.3 \mathrm{~m}$ w.e. $\mathrm{a}^{-1}$, the residual obtained by adding the avalanche contribution to glaciological mass balance.

\section{Hamtah glacier}

In Hamtah glacier, we estimate an avalanche contribution of $1.0 \mathrm{~m}$ w.e. $\mathrm{a}^{-1}$, by requiring that the state has right elevation (2000) and velocity profile ( 2003), and shows reasonable retreat rates. Our modeled retreat rates for the period 1963-2013 is $22 \mathrm{~m} \mathrm{a}^{-1}$ (Fig. 5c), which compares favourably with the observed long-term retreat (Pandey and others, 2011). We do not attempt to fit the recent slowdown of the retreat discussed previously, as we are interested in the long-term mean behaviour of the glacier. This modeled state has a residual mass balance of $-0.5 \mathrm{~m}$ w.e. $\mathrm{a}^{-1}$ once the avalanche term is included. According to the experiment (2), without such significant avalanche feeding, the initial glacier state form 1963 would have slowed down dramatically, with the ablation area getting completely detached by now (Fig. 5c).

\section{Chhota Shigri glacier}

In Chhota Shigri Glacier, where no significant avalanche contribution is expected as discussed before, we have modeled the glacier without any avalanche term and reproduced the observed dynamics of the glacier with just the glaciological mass-balance profile (Fig. 6) (Azam and others, 2014). In this case, we start with a longer steady state $(E L A \sim 4900 \mathrm{~m})$ and apply a step rise of ELA by $150 \mathrm{~m}$. Then an intermediate state is chosen such that it has the right length, retreat rate, thickness and velocity profile. The modeled glacier has an ELA of 5040 m consistent with the observed mean ELA of $5075 \mathrm{~m}$ during the period of 2002-10 (Azam and others, 2012). The simulated glacier shows a retreat of $22.6 \mathrm{~m} \mathrm{a}^{-1}$ from 1990 to 2010, with a mass balance of $-0.6 \mathrm{~m}$ w.e. $\mathrm{a}^{-1}$. This modeled retreat rate is comparable with observed retreat rate of $25 \mathrm{~m} \mathrm{a}^{-1}$ for the period of 1972-2006 (Ramanathan, 2011). On the other hand, the geodetic mass balance of $-0.17 \pm 0.09$ $\mathrm{m}$ w.e. $\mathrm{a}^{-1}$ during $1988-2010$ is somewhat smaller than the modeled value. However, the reported glaciological mass balance of $-0.57 \pm 0.40 \mathrm{~m}$ w.e. $\mathrm{a}^{-1}$ during 2002-12 (Azam and others, 2014) and geodetic mass balance of
$-0.5 \pm 0.3 \mathrm{~m}$ w.e. $\mathrm{a}^{-1}$ during 2000-12 (Vijay and Braun, 2016) match the modeled value. The match of the surfaceelevation profile and velocity profile are also reasonable (Fig. 6). The result of this control experiment for a glacier where avalanches are expected to be insignificant, provides strong support for the general validity of our method.

\section{Model sensitivity}

For all the three glaciers we repeated the experiments with different values of the tunable parameters like $f_{\mathrm{s}}, f_{\mathrm{d}}, s$, and also considered the effect of a $10 \%$ uncertainty of the observed retreat rate and a $10 \%$ uncertainty of the massbalance profile. It turns out that in the model glacier the flow is dominated by slip. Therefore, the uncertainty of the values of $f_{\mathrm{d}}$ does not affect our result. On the other hand, changing $f_{\mathrm{s}}$ by $\sim 10 \%$ disturbs the match between observed and modeled velocity and thickness profile. However, the match can be restored by changing $s$ on the lower part of the bedrock by $\sim 2 \%$. These adjustments of $f_{\mathrm{s}}$ and $s$ changes the estimated avalanche contribution by $\sim 10 \%$, depending on the glacier and the actual values of the parameter. Allowing an uncertainty of retreat rates of the order of $10 \%$, leads to an uncertainty of the estimated avalanche contribution that is $<10 \%$. Other possible sources of uncertainty that are harder to take into account are the effects actual bedrock shape, tributary geometry, the shape of the massbalance profile used and so on. To check the dependence on the mass-balance profile, we apply constant shifts to the profile by $\sim 10 \%$ of the mass balance. This leads to a variation of our avalanche estimate by $\sim 12 \%$. Therefore, we expect an uncertainty of at least $\sim 30 \%$ in the estimated avalanche contributions. However, a larger mass-balance uncertainty would lead to a correspondingly higher uncertainty of the avalanche-strength estimate. Thus the long-term avalanche contributions to accumulation on Satopanth, Dunagiri, and Hamtah glacier are estimated to be $1.8 \pm 0.5,0.7 \pm 0.2$ and $1.0 \pm 0.3 \mathrm{~m}$ w.e. $\mathrm{a}^{-1}$ respectively.

\section{Consistency with other available data}

\section{Mass balance}

The glaciological mass balance for the two Central Himalayan glaciers, Satopanth and Dunagiri Glaciers, are -2.0 $\mathrm{m}$ w.e. $\mathrm{a}^{-1}$ during $2014 / 15$ and $-1.0 \mathrm{~m}$ w.e. $\mathrm{a}^{-1}$ during 1984-90, respectively. The other suspected avalanche-fed Western Himalayan glacier modeled here, Hamtah Glacier, has a mass balance of $-1.45 \mathrm{~m}$ w.e. $\mathrm{a}^{-1}$ during 2000-09 (Shukla and others, 2015). In fact, these are three of the most negative mass-balance values observed in the region (Vincent and others, 2013). These values are considerably more negative than estimated region-wide mean mass 
balance of $-0.5 \mathrm{~m}$ w.e. $\mathrm{a}^{-1}$ in the Himalaya (Cogley, 2011). This is consistent with the possibility that significant accumulation contribution due to a putative avalanche activity in these glaciers might have been missed.

Unlike glaciological method, geodetic method captures glacier-wide changes, whether or not avalanche contributions are present. Therefore, if our method of estimating avalanche contribution is correct, then our estimated avalanche contribution for these three glaciers, when added to the glaciological mass balance should lead to residuals that are similar to the corresponding geodetic mass balance. Indeed, the residual mass balance of $-0.2,-0.3$ and $-0.5 \mathrm{~m}$ w.e. $\mathrm{a}^{-1}$ on Satopanth, Dunagiri and Hamtah Glacier, respectively, are similar to the existing independent geodetic mass-balance estimates. For example, regional-scale geodetic mass-balance estimates from the Western and Central Himalayan glaciers point to a mass loss of $0.33-0.65 \mathrm{~m}$ w.e. $\mathrm{a}^{-1}$ over the past one to four decades (Bolch and others, 2011; Kääb and others, 2012; Gardelle and others, 2013; Vincent and others, 2013; Vijay and Braun, 2016). Also, on Hamtah glacier, the geodetic mass balance during 2000-11 is $-0.45 \pm 0.16 \mathrm{~m}$ w.e. $\mathrm{a}^{-1}$ (Vincent and others, 2013). This consistency of the residual mass-balance values for the three glaciers computed here, with the known geodetic mass-balance measurements indicates reliability of our method of estimating avalanche contribution. In contrast on Chhota Shigri glacier, where no significant avalanche activity is unlikely, all the three estimates namely, the modeled, geodetic and glaciological mass balances are mutually consistent.

\section{The total avalanche contribution and regional precipitation}

A naive expectation regarding the magnitude of the suspected avalanche accumulation is that it should be similar to or less than the total precipitation over the whole avalanche-contributing zone. We compute the ratio of the estimated avalanche accumulation to the product of mean Tropical rainfall measuring mission (TRMM) precipitation and the area of the avalanche-release zone for all the three glaciers. However, the possible uncertainty associated with TRMM precipitation data from the high Himalaya and a potential intensification of precipitation through strong orographic effects due to the high headwalls would mean that theses values are only ball-park estimates. We find that the calculated ratios are $\sim 1.3 \pm 0.4,0.6 \pm 0.2$ and 1.8 \pm 0.5 for Satopanth, Dunagiri and Hamtah Glaciers, respectively. While these values indicate that our estimates are broadly consistent with the potential avalanche accumulation as estimated from local TRMM precipitation rate, they are somewhat larger for Hamtah and Satopanth Glaciers. In spite of the possible uncertainties in the computed ratio, this discrepancy suggests a potential bias in our estimates of the avalanche strength using a simplified flowline model. For example, in Satopanth glacier there are a few tributaries that join the main trunk glacier in the middle ablation zone (Fig. 2a). While modeling the glacier, we have approximated this geometry by that of a simple glacier that shares an identical hypsometry, ignoring the actual tributary configurations. That could be a possible source of the bias for this glacier. However, Hamtah does not have any such complication. We shall investigate these issues further and attempt possible refinements of the flowline model to include the tributaries explicitly in future.

\section{Avalanche control of the glacier dynamics}

The results of our simulations for Hamtah, Satopanth and Dunagiri Glaciers indicates that in these glaciers, extensive avalanches from the vast headwalls contribute more than $95 \%$ of the total accumulation. Therefore, in the long term such avalanche contributions control both the dynamics and the glacier extent. Despite the large uncertainties in our estimates arising out of the assumptions and simplifications involved in our method and limitations due to a lack detailed data, these results underline the necessity of quantification of the magnitude of the avalanche-derived accumulation on a large class of Himalayan glaciers. This is necessary to explain the present length, thinning and retreat patterns of these glaciers. Further, it is also important to develop a scheme to relate the trends of avalanche accumulation to climate variables at the scale of the whole Himalaya. That problem requires progress both in terms of theoretical tools and direct field observation techniques. In this regard, the existing methods of estimating gravitational redistribution of snow [e.g. Gruber, 2007; Bernhardt and Schulz, (2010)], in combination with methods similar to the one presented here could be useful starting points.

\section{CONCLUSIONS}

We have discussed the importance of avalanche derived accumulation on a large class of Himalayan glaciers and the diagnostic criteria to identify such glaciers. Using standard glaciological mass-balance techniques, measurement of this avalanche contribution to the mass balance is extremely difficult. Motivated by that, we have described a simplified numerical flowline model-based method that allows a first order estimation of such an avalanche contribution. The method utilises the available long-term data on glacier dynamics and determines a missing mass-balance term necessary to make the recent multi-decadal dynamics consistent with the glaciological mass balance. Our simplified models for three Himalayan glaciers, namely, Satopanth, Dunagiri and Hamtah Glaciers, demonstrate that the above mentioned avalanche-accumulation contribution dominates the accumulation and exerts overwhelming control over the dynamics of a significant number of Himalayan glaciers. This demands further work on more refined theoretical tools and, more importantly, direct field-measurement techniques to quantify the avalanche activity and their long-term trends in the region. Our control experiment with Chhota Shigri Glacier is consistent with no significant avalanche contribution, asserting the robustness of the method in estimating avalanche contribution to mass balance.

\section{ACKNOWLEDGEMENTS}

We thank the anonymous reviewer, reviewer D I Benn and scientific editor Charles Fierz for very helpful suggestions that led to a significant improvement of the manuscript in our view. $A B$ acknowledges support from DST-SERB grant no SB.DGH-71.2013 and DST-INSPIRE Faculty award (IFA12-EAS-04). The field work on Satopanth Glacier was supported by The Institute of Mathematical Sciences. 


\section{REFERENCES}

Adhikari S and Huybrechts P (2009) Numerical modelling of historical front variations and the 21st-century evolution of glacier AX010, Nepal Himalaya. Ann. Glaciol., 50(52), 27-34

Azam MF and 10 others (2012) From balance to imbalance: a shift in the dynamic behaviour of Chhota Shigri glacier (Western Himalaya, India). J. Glaciol., 58, 315-324 (doi: 10.3189/ 2012JoG11J123)

Azam MF and 5 others (2014) Reconstruction of the annual mass balance of Chhota Shigri glacier, Western Himalaya, India, since 1969. Ann. Glaciol., 55(66), 69-80

Banerjee A and Azam MF (2016) Temperature reconstruction from glacier length fluctuations in the Himalaya. Ann. Glaciol., 57(71), 189-198

Banerjee A and Shankar R (2013) On the response of Himalayan glaciers to climate change. J. Glaciol., 59, 480-490 (doi: 10.3189/ 2013JoG12J130)

Banerjee A and Shankar R (2014) Estimating the avalanche contribution to the mass balance of debris covered glaciers. Cryos. Discuss., 8(1), 641-657

Benn DI and Lehmkuhl F (2000) Mass balance and equilibrium-line altitudes of glaciers in high-mountain environments. Quatern. Int., 65/66, 15-29

Benn DI, Kirkbride MP, Owen LA and Brazier V (2003) Glaciated valley landsystems. Glacial Landsystems, Arnold, London, 372-406

Bernhardt M and Schulz K (2010) Snowslide: a simple routine for calculating gravitational snow transport. Geophys. Res. Lett., 37, 11

Bolch T, Pieczonka T and Benn DI (2011) Multi-decadal mass loss of glaciers in the Everest area (Nepal Himalaya) derived from stereo imagery. Cryosphere, 5(2), 349-358

Cogley JG (2011) Present and future states Himalaya and Karakoram glaciers. Ann. Glaciol., 52, 69-73

Cogley JG and 11 others (2011) Glossary of glacier mass balance and related terms. UNESCO-IHP-VII, Paris, France. [online] Available from: http://unesdoc.unesco.org/images/0019/0019 25/192525E.pdf

Farr TG and 10 others (2007) The shuttle radar topography mission. Rev. Geophys., 45(2)

Gardelle J, Berthier E, Arnaud Y and Kääb A (2013) Region-wide glacier mass balances over the Pamir-Karakoram-Himalaya during 1999-2011. Cryosphere, 7(6), 1885-1886

Gruber S (2007) A mass-conserving fast algorithm to parameterize gravitational transport and deposition using digital elevation models. Water Resour. Res., 43(6)

Hughes P (2008) Response of a Montenegro glacier to extreme summer heatwaves in 2003 and 2007. Geogr. Ann.: Ser. A, Phys. Geogr., 90(4), 259-267

Immerzeel WW, Pellicciotti F and Bierkens MFP (2013) Rising river flows throughout the twenty-first century in two Himalayan glacierized watersheds. Nat. Geosci., 6(9), 742-745

Kääb A, Berthier E, Nuth C, Gardelle J and Arnaud Y (2012) Contrasting pattern of early twenty-first-century glacier mass changes in Himalaya. Nature, 488, 495-498 (doi: 10.1038/nature11324)

Kaser G, Fountain A and Jansson P (2003) A manual for monitoring the mass balance of mountain glaciers. IHP-VI Technical Documents in Hydrology 59. UNESCO, Paris
Kirkbride MP and Deline P (2013) The formation of supraglacial debris covers by primary dispersal from transverse englacial debris bands. Earth Surf. Proc. Land., 38, 1779-1792 (doi: 10.1002/esp.3416)

Kumar V, Mehta M, Mishra A and Trivedi A (2016) Temporal fluctuations and frontal area change of Bangni and Dunagiri glaciers from 1962 to 2013, Dhauliganga Basin, central Himalaya, India. Geomorphology, 284, 88-98

Marzeion B, Jarosch AH and Hofer M (2012) Past and future sealevel change from the surface mass balance of glaciers. Cryosphere, 6(6), 1295-1322

Nagai H, Fujita K, Nuimura T and Sakai A (2014) Southwest-facing slopes control the formation of debris-covered glaciers in the Bhutan Himalaya. Cryosphere, 7, 1303-1314 (doi: 10.5194/tc7-1303-2013)

Nainwal HC, Banerjee A, Shankar R, Semwal P and Sharma T (2016) Shrinkage of Satopanth and Bhagirath Kharak glaciers, India, from 1936 to 2013. Ann. Glaciol., 57(71), 131-139

Oerlemans J (2001) Glaciers and climate change. AA Balkema Publishers, Rotterdam, Netherlands

Pandey P, Venkataraman G and Shukla SP (2011) Study of retreat of Hamtah glacier, Indian Himalaya, using remote sensing technique. In Proceedings of Geoscience and Remote Sensing Symposium (IGARSS), 2011 IEEE International, Vancouver, Canada, 24-29 July 2011, 3194-3197 (doi: 10.1109/IGARSS. 2011.6049898)

Ramanathan AL (2011) Status report on Chhota Shigri Glacier (Himachal Pradesh). Himalayan Glaciology Technical Report No. 1. Department of Science and Technology, Ministry of Science and Technology, New Delhi, 88 pp

Scherler D, Bookhagen B and Strecker MR (2011a) Hillslope glacier coupling: the interplay of topography and glacial dynamics in high Asia. J. Geophys. Res., 116, F02019 (doi: 10.1029/ 2010JF001751)

Scherler D, Bookhagen B and Strecker MR (2011b) Spatially variable response of Himalayan glaciers to climate change affected by debris cover. Nat. Geosci. 4, 156-158 (doi: 10.1038/ngeo1068)

Shukla SP, Mishra R and Chitranshi A (2015) Dynamics of Hamtah glacier, Lahaul \& Spiti district, Himachal Pradesh. J. Ind. Geophys. Union, 19(4), 414-421

Srivastava D and Swaroop S (1992) Glaciological studies on Dunagiri glacier, district, Chamoli, U.P. - Final Report, Rep. Geol. Surv. India

Venkatesh TN, Kulkarni AV and Srinivasan J (2012) Relative effect of slope and equilibrium line altitude on the retreat of Himalayan glaciers. Cryosphere, 6(2), 301-311

Vijay $S$ and Braun M (2016) Elevation change rates of glaciers in the Lahaul-Spiti (Western Himalaya, India) during 2000-2012 and 2012-2013. Remote Sens., 8(12), 1038

Vincent $C$ and 10 others (2013) Balanced conditions or slight mass gain of glaciers in the Lahaul and Spiti region (Northern India, Himalaya) during the nineties preceded recent mass loss. Cryosphere, 7, 569-582 (doi: 10.5194/tc-7-569-2013)

Viste $E$ and Sorteberg A (2015) Snowfall in the Himalayas: an uncertain future from a little-known past. Cryosphere, 9, $1147-1167$ 